\title{
Discussion of the City Sewage Conduit Construction
}

\author{
Yu Tang ${ }^{1 \mathrm{a}}$, Juanjuan $\mathrm{Hu}^{2,3 a}$ \\ ${ }^{1}$ Liaoning Datong Road Construction CO.,LTD. \\ ${ }^{2}$ College of Architecture and Civil Engineering, Beijing University of Technology, Beijing, 100022, \\ P.R.China \\ ${ }^{3}$ Transport Management Institute,Ministry of Transport of the People's Republic of China,Beijing, \\ 101601, P.R.China \\ ahjj1008@sina.com
}

\section{Keywords: Construction Management; Project Quality; Project Safety}

Abstract: The engineering quality is very important. With the development of economy and the project construction increasing, the appearance of jerry-built project causes significant financial losses for the country and imposes threats to the safety of life and property meanwhile quality engineering springs up, so the quality should be taken into account. This article described the constructing process of Baoji high-tech 22th sewage conduit construction engineering: the construction technology and measures is the key point of the process and it illustrates construction details.

\section{Introduction}

In modern society the method of city sewage conduit construction is mainly pipe jacking construction method. In the process it is necessary to excavate the working pit and receiving pit and until the pipe jacking completed, and working pit and receiving pit began laying inspection wells, then backfilled and restored the road, that is he most common construction technology of pipe jacking construction method.

\section{Project Introduction}

Project Characteristics. The project named Baoji high-tech 22th sewage conduit construction engineering has been planed total length of 401.38 meters and all the pipes are made of reinforced concrete with diameter of 500 from pile $0+022$ as the starting point to pile $0+423.380$ as the finish line. It request that the project starts on March 1, 2013 and completed on July 1, 2013.

Site Natural Condition. According to the information provided by the urban meteorological department, the precipitation mainly happens in July to September months, mostly in the form of thundershowers and rainstorms. The highest temperature happening in the mid-July to mid-august and reaches $38^{\circ} \mathrm{C} \sim 39^{\circ} \mathrm{C}$, and it has no great influence on the construction. According to the data provided by the geological department, the region is in the Wei river with about the depth of 1 meter upper and the lower sand.

Construction Situation. The project is Baoji high-tech 22th sewage conduit construction engineering, including construction of major pipes, pre-buried pipelines and inspection wells, as following table 1 . 
Table 1 The Material and Size of Pipes

\begin{tabular}{|c|c|c|c|c|}
\hline name & specification & unit & number & comment \\
\hline reinforced concrete pipe & D500 & M & 401.38 & spigot \\
\hline reinforced concrete pipe & D400 & M & 54 & spigot \\
\hline sanitary sewer manhole & $\Phi 1000$ & set & 10 & \\
\hline
\end{tabular}

Note: There are the pre-buried pipelines in pile $0+125.483$ and pile $0+347.480$.

\section{Construction Preparation}

Construction Progress. According to owner's project period and combining with the company's ability and the selected construction plan, it determines the total project duration time. The construction progress should consider the whole situation and pay attention to the overall effect. The schedule arrangement principle is "the ground after the underground", "the first subject after the affiliated and to short the earthwork processing part of the construction period in order to lay the foundation of project overall work.

Setting-out Survey. According to the design, it can survey the location of the roads center-line and the wells center position, then setting up the center pile. The location of the roads center-line and the wells center position must be checked by the supervision. According to the diameter size and buried depth of the construction pipes, it can determine the groove width's set line on the basis of the rules, and before excavation construction the design unit shall tell all things about the designs. Benchmark controlling system: it should set one benchmark controlling point every 100 meters in accordance with the checking standard, the it can form elevation controlling system.

Raw Material's Procurement and Checking. Raw materials specifications for the engineering and quality are approved by the owners and the supervisors to purchase to the nearest. Checking should be in time according to the relevant provisions of the design and requirements. Once been qualified, the project relevant parties were in the signature.

Temporary Facilitie, Construction Electricity and Water. The water of this project construction is used to trench draining and mixing concrete. The construction water should be nearer to blender. It is necessary to erect the temporary tents at the construction site. The construction electricity is used to consolidate grooves and make the blender work normally.

Arranged Employment Opinion. It is necessary to make the following arrangements to construction process depending on the situation: Firstly it is the sewage conduit construction because the sewage conduit is deeper than rain sewer pipes. The wells' construction is after the completion of the major pipes and pre-buried pipes. The last step is the layering of compacted backfill.

\section{The Plan of Equipment, Personnel and Materials on Site}

Everything should be arranged before constructing. The pipe pillow should be made ahead of time according to the diameter size of the pipe. The blender is on the construction site in advance. Cement, gravel, sand should be on the construction site 5 days before starting construction. Meeting the requirements of pipe-basement templates should be prepared in advance. 


\section{Construction Process and Technical Measures}

The Technical Process of Sewage Conduit. Survey layout $\rightarrow$ the excavation and supporting of grooves (shallow well point dewatering partly) $\rightarrow$ the construction of pipes-basement $\rightarrow$ laying pipes $\rightarrow$ constructing inspection wells $\rightarrow$ close water test $\rightarrow$ backfilling grooves.

The Preparation of Sewage Conduit Construction. In construction, it is necessary to mark the start and finish and to determine the excavation line with white ash according to the design road controlling points.

Marking the elevation at the edge of the road and measuring the elevation every 5 meters in excavation is to control the pipes' slope ratio.

Excavation of Grooves. Because of the sewage pipeline buried deeper,the project is roughly is about $3 \sim 3.5 \mathrm{~m}$, and the soil conditions in the region is : The upper is grain filling giving priority to cohesive soil, and the lower is the grains of sand, so it is necessary to support somewhere for its big liquidity. For this, it is excavated by 1:0.8 of the slope ration in the excavation process. When excavating, it should be reserve a certain margin above the tank bottom elevation in design, it must be manually trim the ground $20 \mathrm{~cm}$ above the tank bottom, in the necessary place for both sides have to support, when trimmed the ground it should be constructed immediately. The pile soil should not be higher than $1.5 \mathrm{~m}$ beside the groove, when putting the pile soil beside the telephone pole and other facilities should be paid attention to a safe distance, not less than 1.5 meters from the groove edge, and construction machinery should park away from the groove edge of not less than 1.0 meters. Due to this project in the wei river edge, shallow underground water level, so in the process of excavation with groundwater seepage, in the projection, it should set channel drains in the bottom, collect the water into the bottom of the channel, into the sump and take the water out use the water pump, the water directly into the drainage channel, to ensure that the bottom of the channel and dry.

Tube Pillow and Pipe Laying. The elevation of concrete foundation should be checked before pipe by level, work it flat manually, and clean up the debris and water on the surface of the foundation, pop up the center pipeline on the foundation, only when the level is up to the standard can make pipe, and control the pipe bottom elevation for prospective. After the acceptance of cushion flat base, you can setup pipes when reached a certain intensity, The first is to right place the pipe pillow, the pillow should be on the center of the pipeline, the distance of each pipe pillow is $75 \mathrm{~cm}$, pipe pillow should be stable and strong. Along out of products in strict accordance with the standards, not use the substandard, in the upstream direction, socket to upstream, socket to downstream, before laid the bell mouth and socket pipes it is necessary to ensure the quality, and must have a quality policy, and certificate of quality. Construction should be clean wash with water. Piping installation using crane to tube, pipe, artificial cooperate with crane. When laying, swing smooth pipe joint, hand chain hoist crane to the translation to the exhaust pipe interfaces, laced by artificial management to adjust to elevation and axis of the pipe joint to make it smooth.

After pipeline completely placed, check carefully whether there is a problem exist, if everything is ok, then do the pipe seam sealing, put the oil into pipe joints, fill in up and down, left and right, finally filled with cement mortar, plaster processing by 1:2, and maintaining.

Pouring Concrete Foundation. After the pipe arrived the required position then start to a form setting, pouring jaasiel, for jaasiel the strength of the concrete foundation requirements for the $\mathrm{C} 15$,this project adopts the C30 concrete foundation. Before pouring it Should paving sand cushion quickly, according with the provisions, the groove width and laying, flat, compaction, after 
that the grains of sand cushion layer prepared in pouring concrete foundation. . Concrete gradation by qualified lab experiment personnel mixture ratio design according to the strength of the design rules, steel template is used for the concrete foundation of the model, After concrete immersion vibrator vibrated, reoccupy plate-type vibrator vibration to flat and smooth. Base casting after the completion of 2 hours cannot be soaked by the rain, and curing. Wait until the concrete base after complete solidification can pull down the template.

Checking Well Masonry Construction. Check well construction must ensure that the full, mortar joint straight, not cracked, dirt and float ash on the surface of the wall must be removed when processing, Chute and borehole wall masonry at the same time, the height requirements of the chute: sewage Wells and flat pipe top, borehole chute should be smooth, there can be no construction waste and other debris. So the well wall with $20 \mathrm{~mm}$ thick waterproof 1:2.5 cement mortar plaster, and the underground water level above $500 \mathrm{~mm}$. Well adopts C30 concrete, cast iron manhole cover and seat must be intact, smooth installation, the position is correct. The project inspection Wells using convergent type. Mortar by mechanical mixing, mixing time not less than 3 minutes, mortar increases with the increasing mix should use, generally to finished within 2 hours, when the temperature is too high should be finished in a shorter period of time, rigorous use overnight mortar.

Trench Backfill Construction. In order to ensure the quality of backfill soil, geotechnical testing, set up in the office at the scene to control of the backfill soil moisture content and compaction density at any time.

Conforming to the requirements of backfill soil water content, when the backfill soil moisture content is too large, according to the weather, the site situation, use dry or mixing lime powder measures, in order to achieve the best water content backfill soil.

In each layer of backfill soil virtual of height is 30 centimeters.

It should be no rubble, brick and other sundry in the backfill.

Segmented backfill on the adjacent segment of backfill should step, don't leak ram.

After completion of each layer of backfilling must be after the supervision and inspectors qualified rear can be carried out under a layer of backfill.

Removal of Support. When dismantle the steel brace it should be meet the following requirement:

It can only pull out the steel column after the backfilling reached the height requirement.

Steel column should be timely backfill after pull column hole.

When the backfill column hole measures should be taken to infill, when using sand filling and filling, can flush for settling, when required by the control surface, usually taken extraction column while grouting method.

\section{Summary}

Sewage pipeline engineering controlling is a comprehensive project, and must be prepared to affect each linked controlling, and all details of inspection work, in the supervision work should fully give play to the role of supervision of the supervision and inspection, pipe, strictly control each link of the well, and ultimately to ensure the project to achieve the requirement of the design and using. 


\section{Reference}

[1] Yi Shen. Modern urban sewage pipeline construction technology. Journal of new technology and new products in China, 2014 (11): 182.

[2] Qiu Li. Discussion of municipal drainage pipeline construction technology. Journal of entrepreneurs world(theory version), 2010 (05): 44-45.

[3]Measures to Ensure Construction Quality of Municipal Drainage Pipeline Work[J]. Shanxi Architechture(2006)

[4]Prevention and treatment of common problems in construction quality of municipal drainage pipeline project. Construction Design for Project, 2005

[5]Traffic Industry Standard of the People's Republic of China, Test Methods of Rock for Highway Engineering(JTG E42-2005)Beijing, People's traffic press

(2005) 